\title{
p104 Binds to Racl and Reduces Its Activity during Myotube Differentiation of C2C12 Cell
}

\author{
Ki Young Choi, ${ }^{1,2}$ Min Sup Lee, ${ }^{1,2}$ Young Jun Cho, ${ }^{2}$ Myong Ho Jeong, \\ Seung Jin Han, ${ }^{3}$ and Seung Hwan Hong ${ }^{1,2}$ \\ ${ }^{1}$ Institute of Molecular Biology and Genetics, Seoul National University, Seoul 151-742, Republic of Korea \\ ${ }^{2}$ School of Biological Sciences, Seoul National University, San 56-1 Shillim-dong, Kwanak-gu, Seoul 151-742, Republic of Korea \\ ${ }^{3}$ School of Biological Sciences, Inje University, Gimhae 621-749, Republic of Korea \\ Correspondence should be addressed to Seung Hwan Hong; shong@plaza.snu.ac.kr
}

Received 30 August 2013; Accepted 12 November 2013; Published 27 January 2014

Academic Editors: K. G. Birukov and M. Chiariello

Copyright (C) 2014 Ki Young Choi et al. This is an open access article distributed under the Creative Commons Attribution License, which permits unrestricted use, distribution, and reproduction in any medium, provided the original work is properly cited.

\begin{abstract}
The p104 protein inhibits cellular proliferation when overexpressed in NIH3T3 cells and has been shown to associate with p85 $\alpha$, Grb2, and PLC $\gamma 1$. In order to isolate other proteins that interact with p104, yeast two-hybrid screening was performed. Racl was identified as a binding partner of p104 and the interaction between p104 and Racl was confirmed by immunoprecipitation. Using a glutathione S-transferase (GST) pull-down assay with various p104 fragments, the 814-848 amino acid residue at the carboxylterminal region of p104 was identified as the key component to interact with Racl. The CrkII which is involved in the Racl-mediated cellular response was also found to interact with p104 protein. NIH3T3 cells which overexpressed p104 showed a decrease of Racl activity. However, neither the proline-rich domain mutant, which is unable to interact with CrkII, nor the carboxy-terminal deletion mutant could attenuate Racl activity. During the differentiation of myoblasts, the amount of p104 protein as well as transcript level was increased. The overexpression of p104 enhanced myotube differentiation, whereas siRNA of p104 reversed this process. In this process, more Racl and CrkII were bound to increased p104. Based on these results, we conclude that p104 is involved in muscle cell differentiation by modulating the Racl activity.
\end{abstract}

\section{Introduction}

The p104, a cell proliferation regulator, was initially identified as a binding protein of phospholipase $\mathrm{C} \gamma 1$ (PLC $\gamma 1$ ). It can also interact with the p85 $\alpha$ subunit of phosphoinositide 3-kinase (PI3K) via its proline-rich (PXXP) motifs [1]. Expression of p104 is increased upon serum starvation, and ectopic overexpression of p104 reduces the growth rate of NIH3T3 cells. This growth inhibition can also be achieved by the overexpression of only the proline-rich region of p104. Interestingly, overexpression of p104 leads to increased levels of p2 $7^{\text {kip1 }}$, a cyclindependent kinase inhibitor, and it inhibits the activities of PI3K that are required for cellular proliferation [1].

Rho GTPases are members of the Ras superfamily, of which more than eleven different mammalian Rho GTPases have been identified; Rho, Rac, Cdc42, Rnd1/Rho6, Rnd2/ Rho7, Rnd3/RhoE, RhoG, RhoBTB, RhoD, TTF/RhoH, and Rif [2]. Like all members of the Ras superfamily, the Rho
GTPases cycle between two conformational states; GTP("active" state) and GDP-bound forms ("inactive" state), by hydrolyzing GTP to GDP. The transition between these two states is tightly regulated by three distinct families of proteins including guanine nucleotide exchange factors (GEFs), GTPase-activating proteins (GAPs), and the guanine nucleotide dissociation inhibitors (GDIs). GEFs activate Rho proteins by catalyzing the exchange of GDP to GTP, whereas there are over 80 Rho GAPs which negatively regulate GTPase function by increasing the intrinsic GTPase activity of Rho proteins $[3,4]$. A family of Rho GDIs also negatively regulates Rho GTPases by binding to the GDP-bound form and maintaining it in this inactive state [5].

Racl, one of the subfamily member of Rho GTPases, plays a pivotal role in many cellular processes including myotube fusion [6], differentiation [7, 8], actin dynamics [9], superoxide production $[10,11]$, cell movement $[12,13]$, proliferation [14-16], apoptosis [17-19], and gene expression [18, 20-23], as 
well as the induction of membrane ruffling and lamellipodia formation upon growth factor stimulation [24]. Racl is also required for Ras-induced transformation [8, 25] and constitutive activation of Racl causes anchorage-independent growth, invasion, and metastasis [16, 26, 27]. The various cellular functions of Racl are achieved through direct or indirect interactions with multiple effector proteins including p21-activated kinase (PAK), MEKK serine/threonine kinases, PI4P5K, PI3K, PLC $\beta 2$, and $67^{\text {phox }}[28]$. Racl has an aminoterminal effector-binding domain encompassing amino acids 26-45 which is essential for the induction of actin polymerization as well as interaction with target enzymes such as PAK and NADPH oxidase [29]. The carboxy-terminal hypervariable domain of Racl at residues $143-175$ has been implicated in membrane association and effector binding [30]. More recently, a third effector site was identified at residues 124-135. Referred to as the insert region, it is involved in direct interaction with effectors controlling the actin reorganization and cellular transformation [31].

Racl is activated by CrkII through DOCK180, a guanine nucleotide exchange factor [32-34]. Crk was originally isolated as the oncogene fusion product of the CT10 chicken retrovirus [35] and the CrkII protein contains an aminoterminal SH2 domain and two SH3 domains [36]. The aminoterminal SH3 domain of the CrkII interacts with several proteins that contain a PXXPXK binding motif, including C3G (a nucleotide exchange factor for Rap1), DOCK180, as well as the Abl tyrosine kinase, tyrosine phosphatase, the p85 subunit of PI3K, and c-Jun N-terminal kinase (JNK) [3739]. Despite the lack of an enzymatic kinase domain, CrkII is thought to play a crucial role in growth factor-stimulated signal transduction and regulation of actin cytoskeleton [40, 41].

In this study, Racl was identified as a new interacting partner of p104 using a yeast two-hybrid screening system. p104 was also shown to be involved in reducing the activity of Rac1 and implicated in myotube differentiation of $\mathrm{C} 2 \mathrm{C} 12$ cells by regulating Racl activity.

\section{Materials and Methods}

2.1. Cell Culture and Transient Transfection. NIH3T3 murine fibroblast and $\mathrm{C} 2 \mathrm{C} 12$ murine myoblast were maintained at $37^{\circ} \mathrm{C}$ in $5 \% \mathrm{CO}_{2}$ in Dulbecco's Modified Eagle's Medium (DMEM) supplemented with $10 \%$ calf serum and $10 \%$ fetal bovine serum, respectively. To generate myotubes, $\mathrm{C} 2 \mathrm{C} 12$ cells were cultured in DMEM supplemented with 2\% horse serum (differentiation medium) for five days. Transient transfection of cells with mammalian expression vectors or siRNA was performed using the Nucleofector System (Amaxa $\mathrm{GmbH}$, Cologne, Germany) according to the manufacturer's guidelines (Table 1).

2.2. Plasmid Construction and Expression of Fusion Proteins. The p104I (amino acid residues 7-352), p104II (353-609), and p104III (611-898) constructs were amplified by PCR, incorporating $5^{\prime}$-EcoRI and $3^{\prime}$-HindIII sites and subsequently subcloned into pCMV Taq2B (Stratagene, La Jolla, CA) and pGEX4T1 vectors (GE Healthcare Bio-Sciences, Piscataway,
TABLE 1: Sequences of siRNA used in p104 knockdown.

\begin{tabular}{lcc}
\hline GFP & $\begin{array}{c}\text { Sense } \\
\text { Antisense }\end{array}$ & $\begin{array}{c}\text { GUUCAGCGUGUCCGGCGAGTT } \\
\text { CUCGCCGGACACGCUGAACTT }\end{array}$ \\
\hline p104-a & $\begin{array}{c}\text { Sense } \\
\text { Antisense }\end{array}$ & $\begin{array}{l}\text { GUGAAGAAGCUGAAGGAGATT } \\
\text { UCUCCUUCAGCUUCUUCACTT }\end{array}$ \\
\hline \multirow{2}{*}{ p104-b } & $\begin{array}{c}\text { Sense } \\
\text { Antisense }\end{array}$ & UGGCGUAAGAGGAGAGAGATT \\
\hline \multirow{2}{*}{ p104-c } & $\begin{array}{c}\text { Sense } \\
\text { Antisense }\end{array}$ & GUGAAGAGACUCUGCUUGCAAGAGATT \\
& UCUCUCUCUCUUCACTT \\
\hline
\end{tabular}

NJ). The p104III-1 (611-726), p104III-2 (698-814), p104III3 (783-898), p104III-3A (783-848), and p104III-3B (870898) were amplified and subcloned into KpnI/EcoRI sites of pGEX4T1. The C-terminal truncation mutants of RhoA and Cdc42 were amplified by PCR from mouse RhoA and Cdc42 cDNA as templates and the product was subcloned into HindIII/XhoI sites of pEGFP-C1 (Clontech, Palo Alto, $\mathrm{CA})$. Various GST fusion proteins were induced and purified according to previously described procedures [42].

2.3. Yeast Two-Hybrid Screening. Yeast two-hybrid screening was performed using the MATCHMAKER yeast two-hybrid system (Clontech) according to the manufacturer's protocols. Briefly, p104 cDNA (amino acids 140-899) was cloned into pGBT9 to produce a fusion protein containing galactosidase4 (GAL4) DNA-binding domain. This p104 construct and plasmids encoding the adult mouse brain cDNA library fused to the GAL4 activation domain were then transformed into the yeast strain Y190. Positive colonies which grew on plates lacking His, Leu, and Trp were selected. Interaction was further confirmed by a $\beta$-galactosidase filter assay. Plasmid DNAs were isolated from positive yeast colonies, transformed into $E$. coli and the nucleotide sequences of the positive clones were determined.

2.4. Fluorescence Microscopy. NIH3T3 cells were grown on coverslips in 6 well plates and transfected using FuGENE 6 (Roche Diagnostics, Indianapolis, IN) with the pEGFP C1p104 plasmid. After $24 \mathrm{~h}$, cells were washed twice with PBS and then fixed with $4 \%$ paraformaldehyde or methanol (in 1x PBS) for $30 \mathrm{~min}$ followed by permeabilization with $0.3 \%$ Triton X-100 (in 1x PBS) for $20 \mathrm{~min}$. The coverslips were blocked with $0.5 \%$ bovine serum albumin and incubated with Racl or lamin A/C antibody (Santa Cruz Biotechnology, Santa Cruz, CA) for $2 \mathrm{~h}$ at $4^{\circ} \mathrm{C}$ followed by Rhodmaineconjugated anti-rabbit antibody (Jackson ImmunoResearch, West Grove, PA).

2.5. Antibodies and Western Blot Analysis. A rabbit antibody to p104 was generated against a p104 fragment (residue 450-803) as described previously [1]. Antibodies for FLAG (M2) and GFP (clones 7.1 and 13.1) were purchased from Sigma-Aldrich Co. (St. Louis, MO) and Roche Diagnostics, respectively. Antibodies for CrkII (sc289) were obtained from Santa Cruz Biotechnology (Santa Cruz, CA). Anti-mouse or anti-rabbit IgG conjugated to horseradish peroxidase 
was purchased from Jackson ImmunoResearch (West Grove, PA). The expression of the constructs was determined by immunoblotting according to previously published methods [1].

2.6. Immunoprecipitation and GST Pull-Down Assay. Cultured cells were collected and washed with PBS and suspended in extraction buffer ( $25 \mathrm{mM}$ HEPES ( $\mathrm{pH}$ 7.4), $50 \mathrm{mM} \mathrm{NaCl}, 1 \%$ Triton X-100, 10\% glycerol, 0.1 mM PMSF, $0.1 \mathrm{mM}$ pepstatin, $0.1 \mathrm{mM}$ antipain, $0.2 \mathrm{mM}$ leupeptin, $10 \mu \mathrm{g} / \mathrm{mL}$ aprotinin, $1 \mathrm{mM}$ benzamidine, $15 \mathrm{mM} \mathrm{NaF}$, and $1 \mathrm{mMNa}_{3} \mathrm{VO}_{4}$ ). To prepare the mouse brain extract, tissue was dissected and grinded using a Polytron homogenizer. In both cases, the extracts were then incubated on ice for $15 \mathrm{~min}$. After lysates were centrifuged at $14,000 \times \mathrm{g}$ for $10 \mathrm{~min}$, clarified proteins $(2 \mathrm{mg})$ were incubated with the appropriate antibodies for $3 \mathrm{~h}$ at $4^{\circ} \mathrm{C}$ with continuous agitation. To collect immune complexes, $30 \mu \mathrm{L}$ of protein A Sepharose $4 \mathrm{~B}$ (GE Healthcare Bio-Sciences) was added to the mixture and incubated for a further $2 \mathrm{~h}$. For the GST pull-down assay, glutathione-Sepharose 4B (GE Healthcare Bio-Science) beads bound with GST fusion proteins were incubated with prepared cell or brain extract. The immunoprecipitates or GST complexes were washed three times with extraction buffer and then resuspended in 1x SDS-PAGE sample buffer. Proteins bands were detected by immunoblotting.

2.7. RT-PCR. Total RNA was isolated from $\mathrm{C} 2 \mathrm{C} 12$ cells using TRIzol (Invitrogen, Carlsbad, CA). Two micrograms of total RNA was primed with a mixture of $0.5 \mu \mathrm{g}$ oligo-dT primer and mixed with $10 \mathrm{mM}$ DTT, $10 \mathrm{mM}$ of each dNTP, $5 \mathrm{x}$ first strand buffer, and MMLV reverse transcriptase (Promega, Madison, WI) for reverse transcription. Using these mixtures as templates, PCR was performed with primer sets listed below; Primers for p104 were sense, $5^{\prime}$ GGT GAA GAA GCT GAA GGA G $3^{\prime}$; antisense, $5^{\prime}$ GGA TTT TCA GGG ATT TCT AC $3^{\prime}$. Primers for Myogenin were sense, $5^{\prime}$ ATG GAG CTG TAT GAG ACA $3^{\prime}$; antisense, $5^{\prime}$ CTC CTG GGT TGG GAC CGA $3^{\prime}$. Primers for $\alpha$-Actin were sense, $5^{\prime}$ CAC CAA GGT GTC ATG GTA $3^{\prime}$; antisense, $5^{\prime}$ GCT CTT CTC CAA GGA GGA 3'.

2.8. Racl Activity Assay. For affinity precipitation of GTPbound Racl, cells were washed with ice-cold PBS and incubated with the extraction buffer. The cleared lysates were then incubated with GST-PAK $(25 \mu \mathrm{g})$ precoupled to glutathioneSepharose for $1 \mathrm{~h}$ with continuous agitation. The beads were washed three times with wash buffer $(20 \mathrm{mM}$ HEPES [pH 7.5], $10 \mathrm{mM}$ potassium acetate, $50 \mathrm{mM} \mathrm{NaCl}, 1 \mathrm{mM}$ EGTA, $10 \%$ glycerol, and $50 \mathrm{mM} \mathrm{NaF}$ ). Beads were resuspended in reducing $1 \mathrm{x}$ SDS sample buffer and boiled for $3 \mathrm{~min}$. Samples were run on $12 \%$ SDS-PAGE gels before immunodetection was performed with an anti-Racl antibody.

2.9. JNK Activity Assay. Using Radioimmunoprecipitation (RIPA) buffer (25 mM Tris HCl, pH 7.6, $150 \mathrm{mM} \mathrm{NaCl}, 1 \% \mathrm{NP}-$ $40,1 \%$ sodium deoxycholate, $0.1 \%$ SDS), cell extracts were incubated for $2 \mathrm{~h}$ at $4^{\circ} \mathrm{C}$ with $0.5 \mu \mathrm{g}$ of anti-JNK1 antibody
(Santa Cruz Biotechnology). The JNK1 antibody was recovered by the addition of $30 \mu \mathrm{L}$ of protein A-Sepharose beads $(0.03 \mathrm{~g} / \mathrm{mL})$ and incubated for $2 \mathrm{~h}$ at $4^{\circ} \mathrm{C}$. Beads were collected by centrifugation and washed three times with RIPA buffer. Kinase assays were initiated by the addition of reaction buffer $\left(2 \mathrm{mM} \mathrm{Na}_{3} \mathrm{VO}_{4}, 20 \mathrm{mM} \mathrm{DTT}\right.$, and $100 \mathrm{mM} \mathrm{MgCl}$ ), $3 \mu \mathrm{g}$ GST c-Jun, and $\left[\gamma_{-}{ }^{32} \mathrm{P}\right]$ ATP $(6,000 \mathrm{Ci} / \mathrm{mmol})$. After incubation for 1 hour at $30^{\circ} \mathrm{C}$, reactions were terminated by the addition of an equal volume of $2 x$ SDS sample buffer and boiling. Phosphorylated c-Jun was resolved by 12\% SDS-PAGE gels and visualized by autoradiography. To check the effect of p104 overexpression on ERK activity, serum-starved cells were treated with $50 \mathrm{ng} / \mathrm{mL}$ PDGF BB for $5 \mathrm{~min}$. Fifty $\mathrm{mg}$ of each cell lysate was separated on 10\% SDS-PAGE and analyzed by immunoblot analysis using a phosphorylated form specific Erk antibody (Cell Signaling Tech. Inc., Danvers, MA).

\section{Results}

3.1. Identification of Racl as a Binding Partner of p104. To isolate the protein(s) that interact with p104, yeast two-hybrid screening was employed with p104 (amino acids 140-899) as a bait in combination with the mouse brain cDNA library. The bait contains proline-rich region of p104, which interacts with PLC $\gamma 1$ and p85 $\alpha$, as well as spectrin repeats [1]. From over 40,000 colonies screened, 9 positive clones that specifically interacted with p104 were isolated and their nucleotide sequences were determined. One of the isolated clones was found to be Racl (Figure 1(a)), which is widely known to play a key regulatory role in various cellular processes such as proliferation, apoptosis, and gene expression as well as cell movement [10,12-17, 19-21]. When immunoprecipitation analysis was performed with mouse brain extracts, Rac1 was detected in the coimmunoprecipitated fraction with an antibody against p104 (Figure 1(b)).

The localization of p104 and Racl in intact cells was investigated by fluorescent and confocal microscopy. The EGFP-p104 was predominantly localized to the nuclear membrane where lamin protein is present (Figure 1(c), lower panel). The staining pattern for p104 and Racl confirmed in vivo colocalization of these two proteins in NIH3T3 cells (Figure 1(c), upper panel). p104 was also found in the cytoplasm of transfected cells as a strong fluorescent structure which remains to be identified.

The peptide region in Racl that was isolated as a binding partner of p104 by yeast two-hybrid screening (residues 101180) contains a polybasic region which is common to the carboxy-terminus of Ras and Rho family members. The region promotes interaction with other binding partners [43]. To determine whether p104 could also interact with the polybasic region of other Rho GTPases, GFP-fused carboxyterminal fragments of Racl, RhoA, and Cdc42 were transfected into NIH3T3 cells. Only Racl and not RhoA or Cdc42 coimmunoprecipitated with p104 (Figure 1(d)), indicating that p104 interacts specifically with Racl.

3.2. The Carboxy-Terminal Region of p104 Is Involved in the Interaction with Racl. The fragments of FLAG-tagged 


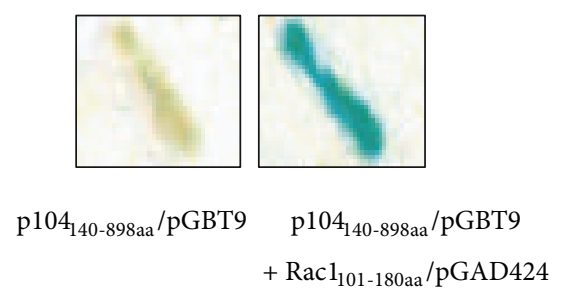

(a)
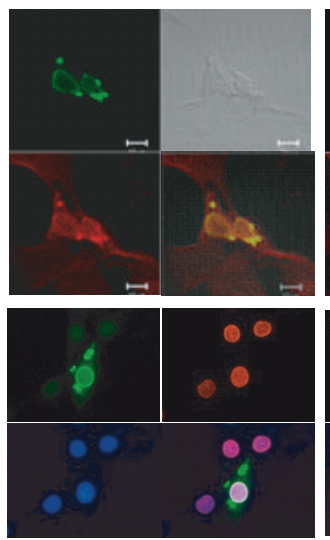

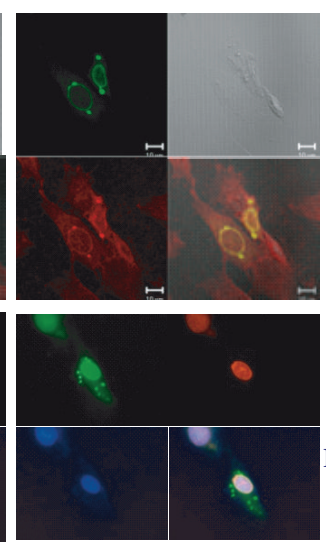

(c)

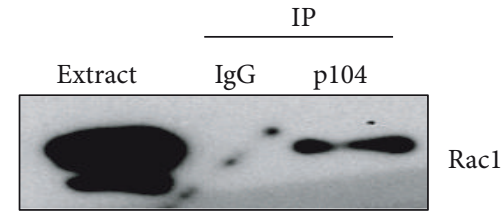

(b)

$$
\begin{array}{c|l}
\text { p104 } & \begin{array}{l}
\text { Bright } \\
\text { field }
\end{array} \\
\hline \text { RacI } & \text { Merge }
\end{array}
$$

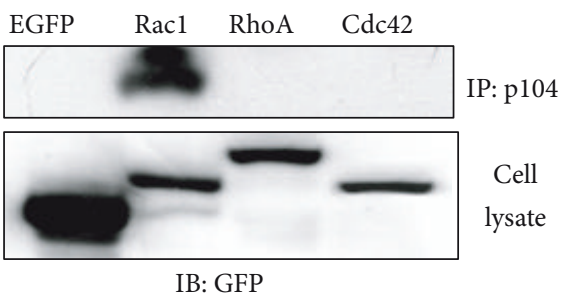

(d)

FIgURE 1: Racl was isolated as a binding protein of p104. (a) The DNA-encoding p104 (amino acids residue 140-898) was inserted into the EcoRI/Pst Isite of a GAL4 DNA-binding domain vector pGBT9. After colony selection on plates lacking Trp, His, and Leu, $\beta$-galactosidase assay was performed on the filter. Racl clones were isolated as a binding partner of p104. (b) Using anti-p104 serum, immunoprecipitation was performed with mouse brain extract and analyzed by Western blotting with an anti-Racl antibody. Immunoprecipitation using an unrelated antibody (IgG) was used as a negative control. (c) Colocalization of p104 and Rac1 in NIH3T3 cells. NIH3T3 cells were grown on cover slips in 6 well plates and transfected with the pEGFP C1-p104 plasmid. After $24 \mathrm{~h}$, cells were fixed and stained with a Racl or lamin antibody followed by a Rhodamine-conjugated anti-rabbit antibody. Fluorescence was observed using a confocal microscope (upper eight panels) or fluorescence microscope (lower eight panels). (d) p104 was specifically associated with Racl. The carboxy-terminal domain of Racl, RhoA and Cdc42 was fused with EGFP and transfected into C2C12 cells. After $24 \mathrm{~h}$, cell lysates were immunoprecipitated with anti-p104 serum and Western blot analysis was performed using an anti-GFP antibody. The expression of EGFP-fused Racl, RhoA, and Cdc42 is shown as a control in the lower panel.

p104 (Figure 2(a), amino acids 3-352, 353-609, and 611898) were transfected into NIH3T3 cells and immunoprecipitated with an anti-FLAG antibody. As shown in Figure 2(b), Racl coimmunoprecipitated with full-length p104 and the fragment containing amino acids 611-898. This result was confirmed by in vivo interaction between p104 and Racl through the carboxy-terminal region of p104. When a carboxy-terminal deletion mutant or the carboxy-terminal fragment of GFP-fused p104 was transfected into NIH3T3 cells, Racl coimmunoprecipitated with the constructs containing the carboxy-terminal region of p104 (Figure 2(c), lanes 3, 9) while the deletion of the carboxy-terminal region abolished the interaction with Racl (Figure 2(c), lane 6). To define the region of p104 responsible for interaction with Racl, various GST-fused p104 constructs were prepared and a GST pull-down assay was performed. Mouse brain extract was incubated with various immobilized GST-fused p104 constructs and bound protein complexes were subjected to immunoblotting with a Racl antibody. The GST pull-down assay revealed that the carboxy-terminus of p104, specifically the short fragment containing amino acids 814-848, could interact with Racl
(Figure 2(d)). These results indicate that this 34 amino acid fragment in the carboxy-terminal region of p104 is necessary for interaction with Racl in vivo.

3.3. p104 Also Interacts with CrkII in addition to Racl. The adapter protein CrkII mediates the formation of multiprotein signaling complexes in response to a variety of extracellular stimuli and regulates cytoskeleton dynamics, cell motility, and phagocytosis in a Racl-dependent manner [34, 44, 45]. To further understand the roles of p104 in the Racl signaling pathway, the association of p104 with CrkII was investigated. As shown in Figure 3(a), CrkII could be coimmunoprecipitated with p104 just like Racl. To define more precisely which region within the p104 protein interacts with CrkII, a GST pull-down assay was carried out with GST-fused p104 fragments. As shown in Figure 3(b), CrkII could bind to the central region of p104 (amino acids 353-609). The central region of p104 contains three proline-rich (PXXP) motifs that are known to interact with the SH3 domain. Since CrkII contains an $\mathrm{SH} 2$ and two $\mathrm{SH} 3$ domains, it was investigated whether p104 directly interacts with CrkII 


\begin{tabular}{|c|c|c|c|c|}
\hline FL-p104 & Flag & SR & \begin{tabular}{|l|l|} 
SR & $S R$ \\
\end{tabular} & \begin{tabular}{|l|l|l|} 
SR & SR \\
\end{tabular} \\
\hline 3-352a.a (I) & Flag & SR & \begin{tabular}{|l|l||} 
SR & $S R$ \\
\end{tabular} & \\
\hline 353-609a.a (II) & & & Flag & $S$ \\
\hline 611-898a.a (III) & & & & 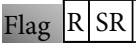 \\
\hline
\end{tabular}

(a)

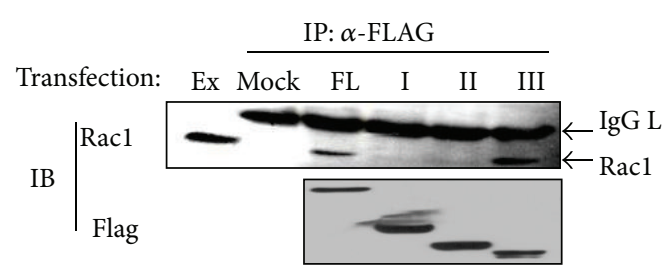

(b)

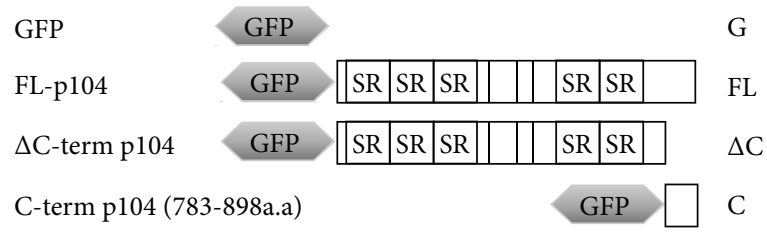

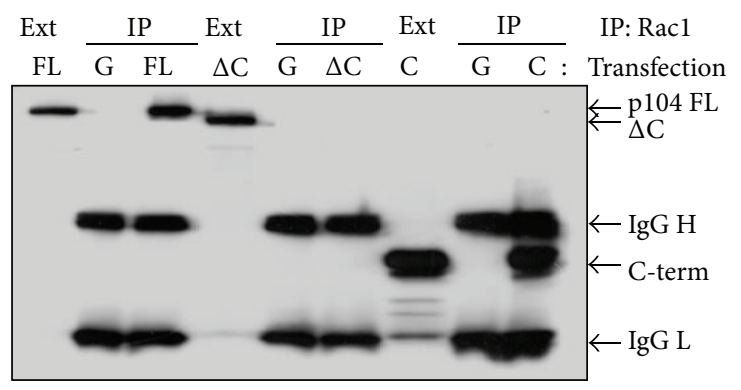

IB: GFP

(c)
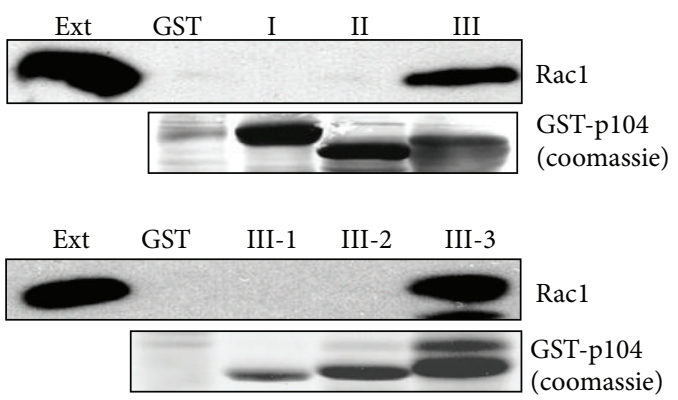

783-898a.a (III-3)

783-848a.a (III-3A)

849-898a.a (III-3B)

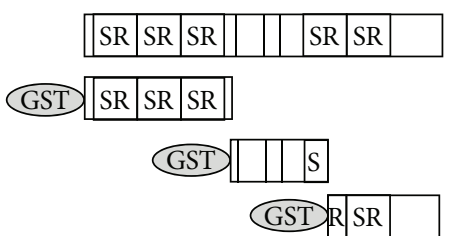

GST RS

GST SR
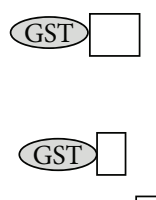

GST

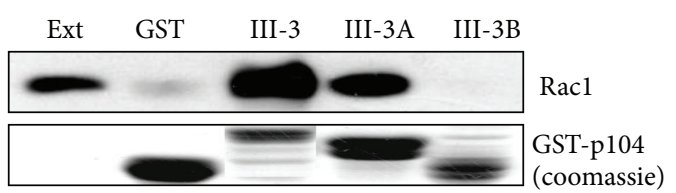

(d)

FIGURE 2: The carboxy-terminal region of p104 was essential for the interaction with Racl. (a) Schematic representation of the constructs used in this experiment. p104 was divided into three regions and inserted into the pCMV Taq2B vector. Full-length (FL) 104 contains the entire open reading frame (ORF), and constructs I, II, and III contain 7-352, 353-609, and 611-898 amino acid residues, respectively. (b) p104 interacts with Racl through the carboxy-terminal 611-898 amino acid region. NIH3T3 cells were transfected with a Flag-tagged p104 construct. After 24 h, 2 mg of clarified cell lysates was immunoprecipitated with an anti-Flag antibody followed by Western blot analysis using an anti-Racl antibody (upper panel). The immunoprecipitated Flag-tagged protein was confirmed with an anti-FLAG antibody (lower panel). (c) The carboxy-terminal region of p104 is required for the association with Racl in mammalian cells. Full-length p104 (FL), carboxy-terminal deleted p104 $(\Delta \mathrm{C})$, and carboxy-terminus of p104 (C) were inserted into a GFP expression vector $(\mathrm{G})$, and the constructs were transfected into NIH3T3 cells. Twenty-four hours after transfection, the interaction between various truncated forms of p104 and Racl was assayed by immunoprecipitation with the anti-Racl antibody followed by Western blot analysis using an anti-GFP mouse monoclonal antibody. Ext: cell extract, IgG H: immunoglobulin heavy chain, and IgG L: immunoglobulin light chain. (d) The 814-848 residue of p104 is required for the association with Racl. Two micrograms of GST-fused p104 I, II, and III was used for the GST pull-down assay. Prepared GST-fused p104 I, II, and III were incubated with $1 \mathrm{mg}$ of mouse brain extract, and bound proteins were then subjected to Western blot analysis to detect Racl. p104 III (amino acid residues 611-898) was subdivided into three parts, consisting of residues 611-726 (III-1), 698-814 (III-2), and 783-898 (III-3). Each DNA fragment was inserted into a pGEX 4T1 vector and a GST-pull-down assay was carried out. Again, p104III-3 was divided into III-3A (783-848) and III-3B (870-898) and then inserted into the pGEX 4 T1 vector. Each construct was used in the in vitro binding assay as described above. A coomassie brilliant blue stained SDS-PAGE gel showed that equal amounts of fusion proteins were used. 


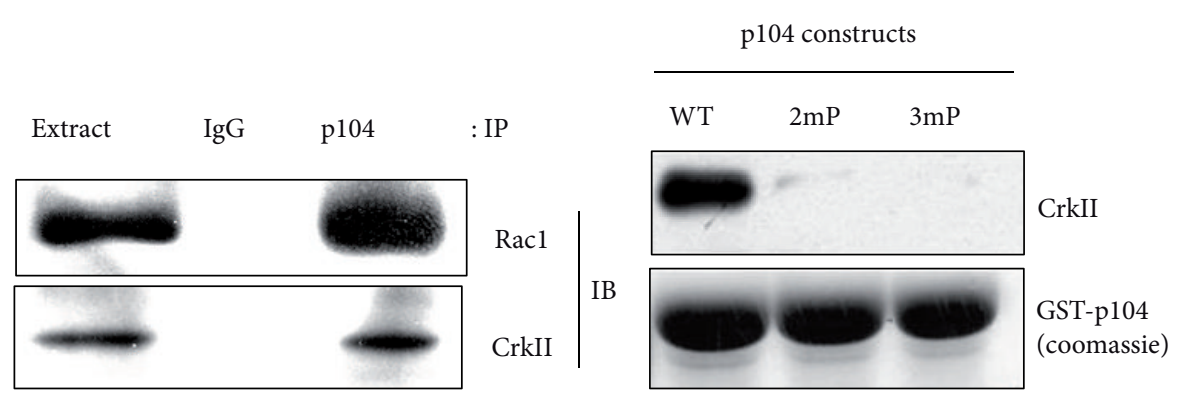

(a)

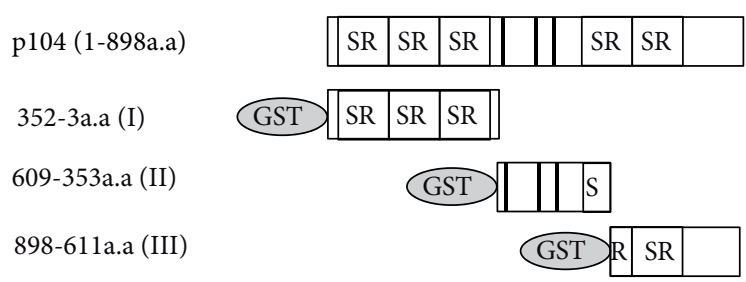

(c)

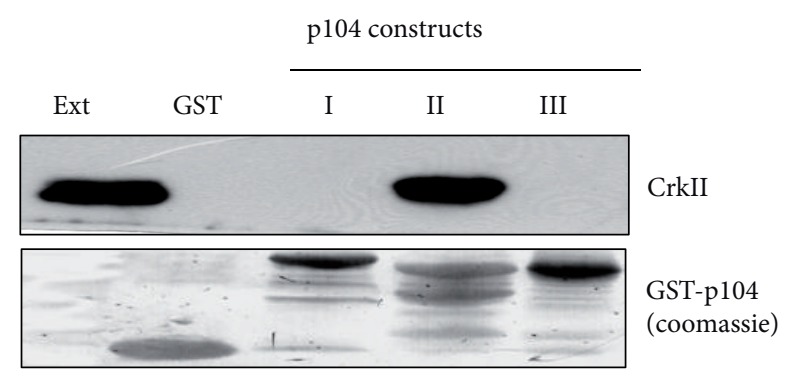

(b)

FIGURE 3: p104 was specifically associated with Rac1. (a) p104 interacted with CrkII as well as Racl. After immunoprecipitation was performed with the p104 antibody, the presence of CrkII and Racl in the precipitated immune complex was analyzed by Western blot with anti-CrkII and anti-Racl antibodies, respectively. (b) CrkII and Racl bind to distinct regions of p104. GST-fused p104 I, II, and III proteins linked to glutathione-Sepharose beads were incubated with mouse brain extract and then bound proteins were analyzed by Western blot with antibodies against CrkII and Racl. (c) p104 directly interacts with CrkII through the proline-rich region. Mouse brain extract was incubated with GSTp104 (WT, wild type), GST-2mp (second proline-rich motif mutant), and GST-3mp (third proline-rich motif mutant) immobilized onto glutathione-Sepharose beads. Bound proteins were analyzed by Western blot with an anti-CrkII antibody. A coomassie brilliant blue stained SDS-PAGE gel showed that equal amounts of fusion proteins were used.

through its PXXP motifs. As the second and third prolinerich motifs in p104 are essential for the cell cycle inhibitory function of p104 [1], point mutations were introduced in the second or third PXXP motifs ( $2 \mathrm{mP}$ and $3 \mathrm{mP})$ and binding activities with CrkII were tested in the GST pull-down assay. As shown in Figure 3(c), mutations in the PXXP motifs resulted in a dramatic decrease in the binding activity with CrkII, suggesting that the interaction between p104 and CrkII occurs through the PXXP motifs of p104.

3.4. p104 Decreases Rac1 Activity. One of the well-known characteristics of Rho GTPases is that they bind to their effectors in an active GTP-bound form. This property was used to measure the relative amount of GTP-bound GTPases in cells by pull-down experiments with the GTPase binding domain of PAK. To investigate the influence of p104 on the activity of Racl, wild-type p104 was transfected into NIH3T3 cells. When the GTP-bound (active) form of Racl was precipitated using GST-PAK fusion proteins precoupled to GSH-beads, the amount of GTP-bound Racl was decreased in wild-type p104 transfectant (Figure 4(a)). The mutant in second proline-rich motif $(2 \mathrm{mP})$ and $\Delta \mathrm{C}$-terminal mutant of p104 could not attenuate the Racl activity, unlike the wildtype p104 transfectant (Figure 4(b)). The mutation in the proline-rich motif of p104 did not affect the binding capacity with Racl, whereas carboxy-terminal deletion of 104 could not interrupt the interaction with CrkII (Figure 4(c)). Taken together, these results suggest that the interaction of p104 with CrkII as well as Racl might be a critical determinant for the regulation of Racl activity.

Since it has been reported that Racl activates the mitogenactivated protein kinase JNK $[14,19,46]$ and phorbol 12 myristate 13-acetate (PMA), a well-known stimulator for JNK induces the phosphorylation of p104 [1]; the relationship between p104 and Racl in JNK activation was subsequently analyzed. When cells were treated with PMA, the degree of phosphorylation of GST-Jun, a substrate of active JNK, was reduced in the p104 overexpressed NIH 3T3 cells (Figure 4(d), upper panel). However, the activation of Erk was not affected by p104 overexpression upon the addition of PDGF BB, an Erk signal cascade stimulator (Figure 4(d), lower panel). Thus, our results suggest that p104 may inhibit JNK activity through the reduction of Racl activity.

3.5. More Racl Interacts with p104 during Myoblast Differentiation. Recently, it was reported that Rho family proteins play a critical role in muscle differentiation. In the absence of mitogenic stimuli, proliferating myoblasts synchronously withdraw from the cell cycle, elongate, adhere, and finally fuse together to form myotubes. The amount of GTP-bound Racl, the active form, was high in proliferating myoblasts and was significantly reduced after the induction of differentiation [47]. To test the possibility that p104 might be involved in the process of myoblast differentiation, $\mathrm{C} 2 \mathrm{C} 12$ myoblast 


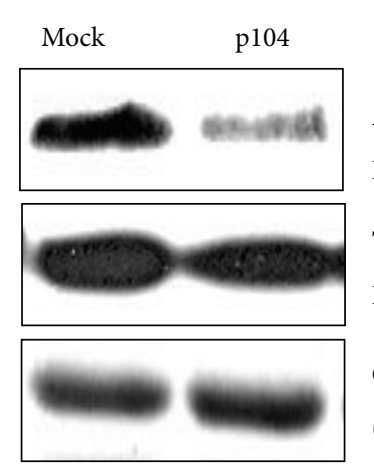

(a)

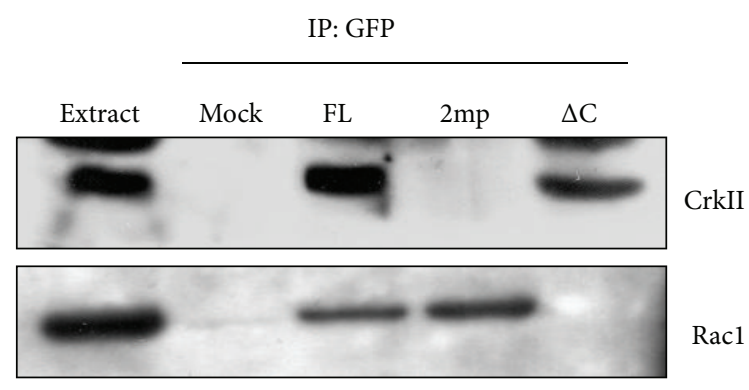

(c)

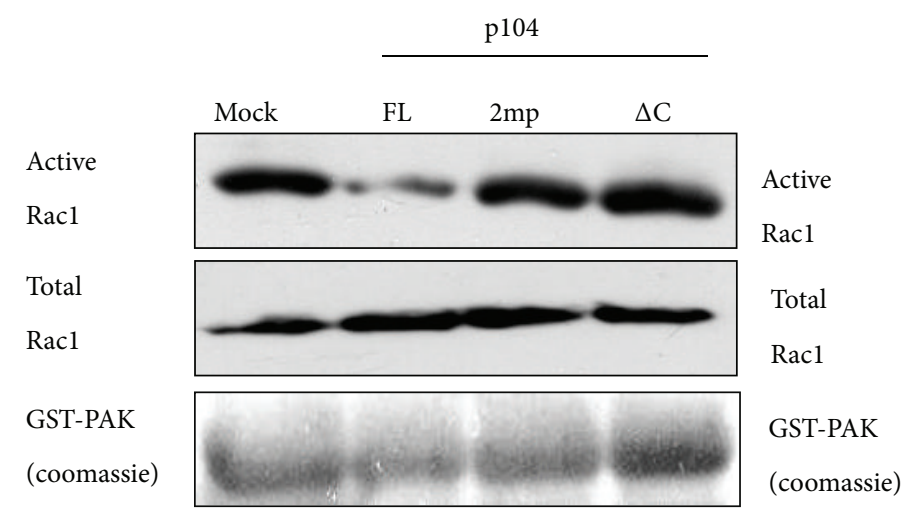

(b)

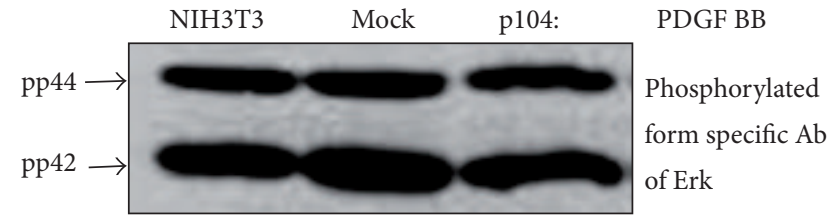

(d)

FIgURE 4: The interaction of p104 with CrkII decreased the activity of Racl. (a) NIH3T3 cells were transfected with empty vector (Mock) or p104 constructs. After $24 \mathrm{~h}$ of transfection, the amount of GTP-bound (active) Racl was determined by GST-PAK pull-down analysis, followed by Western blotting with an anti-Racl antibody (upper panel). $50 \mu \mathrm{g}$ of cell lysate was used for Western blot analysis with an antiRacl antibody to check the total amount of Racl (middle panel). The amount of GST-PAK used in this assay was assessed by coomassie brilliant blue staining (bottom panel). (b) NIH3T3 cells were transfected with GFP-tagged full-length p104 (FL), second proline-rich motif mutant $(2 \mathrm{mp})$ and carboxy-terminal deletion mutant $(\Delta \mathrm{C})$. The level of GTP-bound Racl was measured by GST-PAK pull-down analysis, followed by Western blotting with anti-Racl antibody. (c) Lysates from NIH3T3 cells transfected with GFP-tagged full-length p104, 2mp mutant, and carboxy-terminal deletion mutant were immunoprecipitated with an anti-GFP antibody, and then Western blot analysis was performed with anti-CrkII (upper panel) and anti-Racl antibodies (lower panel). (d) Inhibition of JNK activity by p104 overexpression. To measure the JNK activity, cells were serum-starved for $12 \mathrm{~h}$ and then treated with $5 \mu \mathrm{M}$ PMA/ionomycin for $5 \mathrm{~min}$. JNK was immunoprecipitated and kinase assays were performed using GST c-Jun as a substrate (upper panel). After treatment with $50 \mathrm{ng} / \mathrm{mL}$ PDGF BB, $50 \mu \mathrm{g}$ of each cell lysate was separated on SDS-PAGE gel and they were analyzed by Western blot using an anti-active ERK antibody to check the Erk activity (lower panel).

cell differentiation was induced by replacing the growth medium with differentiation medium when cells reached confluence. C2C12 cells underwent morphological change and elongation and formed small myofibers after the addition of differentiation medium (Figure 5(A)). When the Rac1 activity assay was performed, a decrease in Racl activity was readily detected after the induction of differentiation (Figure 5(B)). As shown in Figure 5(C), the expression levels of p104 mRNA and protein were elevated after incubation in differentiation medium. The increase in myogenin (a muscle regulatory factor) and $\alpha$-actin (a skeletal muscle-specific gene) transcripts also indicated muscle differentiation. When C2C12 differentiation was induced, more Racl and CrkII were shown to interact with p104 (Figure 5(D)), although protein levels of Racl and CrkII were unchanged during the differentiation process. These results suggest that p104 might be involved in muscle differentiation by sequestering Racl and CrkII and thereby decreasing the active Racl.
To confirm the role of 104 in the myotube differentiation, p104 was overexpressed in the $\mathrm{C} 2 \mathrm{C} 12$ cell. In the differentiation media ( $2 \%$ horse serum), the overexpression of p104 caused the induction of differentiation in a shorter period of time compared to nontransfected cells (Figure 5(E), compare (g) with (o)). Interestingly, the degree of differentiation of p104 transfected cells in the nondifferentiation media $(10 \%$ FBS) is higher than that of nontransfected and differentiation media added cells (Figure 5(E), (h) versus (l)). In contrast, three sets of siRNAs against p104 partially inhibited the myotube formation (Figures $6(\mathrm{~A})$ and $6(\mathrm{~B})$ ). This result strongly supports our claim that p104 regulates the myotube differentiation.

\section{Discussion}

In this study, a novel interaction between carboxy-terminal portion of p104 and Racl was examined using several 


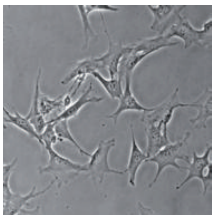

Undifferentiated $\mathrm{C} 2 \mathrm{C} 12$

(a)

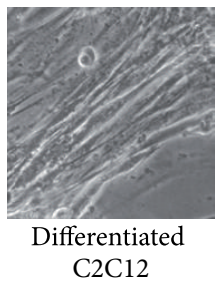

(b)

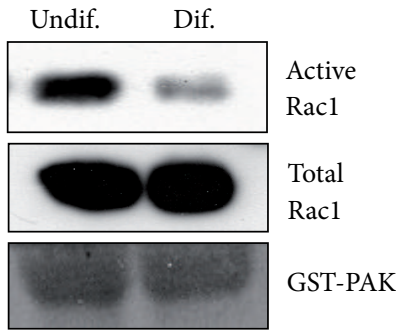

(B)

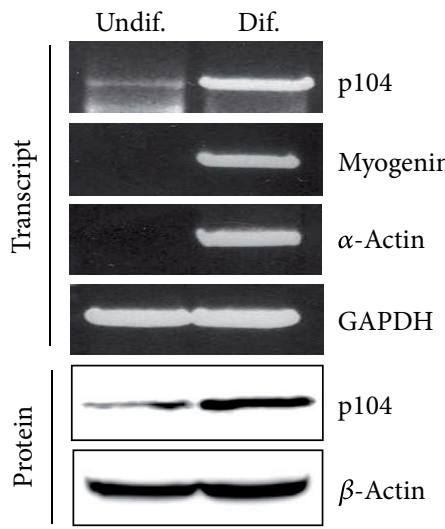

(C)

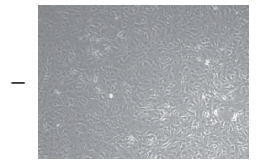

(a)

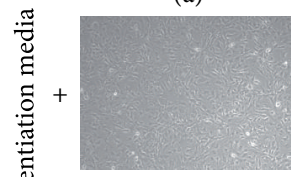

(e)

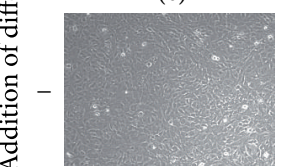

(i)

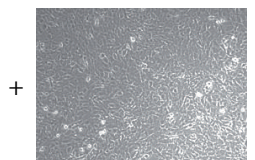

0

(m)

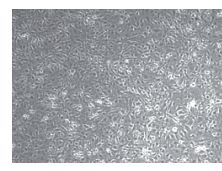

(b)

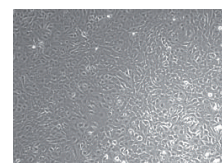

(f)

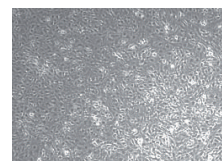

(j)

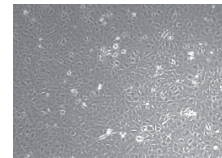

1

(n)

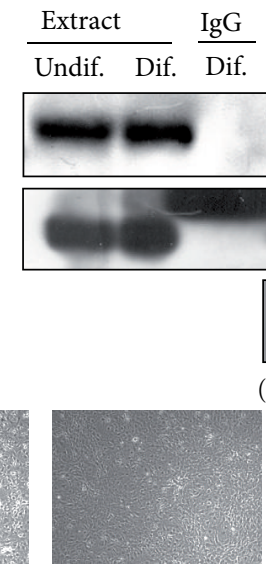

(c)

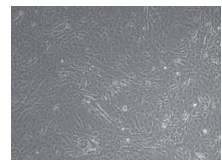

(g)

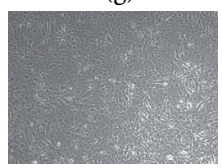

(k)

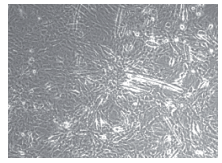

3

(o)
(D)

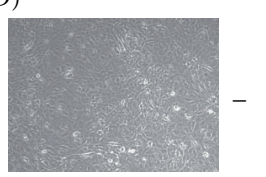

(d)

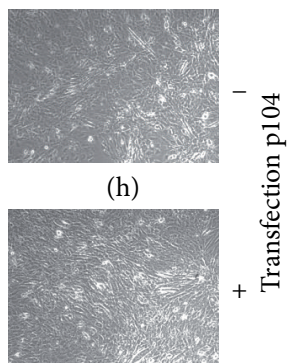

(1)

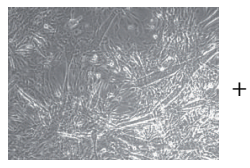

5

(p)

FIGURE 5: Interaction of p104 with Rac1 and CrkII during C2C12 differentiation. (A) C2C12 cells were grown to confluence (a) and then placed in differentiation medium for 5 days to induce the differentiation into myotube formation (b). (B) The activity of Racl was decreased during C2C12 differentiation. The amount of GTP-bound Racl in cell lysates prepared from undifferentiated (Undif.) or differentiated (Dif.) myoblasts was analyzed by GST-PAK pull-down analysis. Racl-GTP (active form) and total Racl from the same extracts were detected by Western blotting with Racl antibody. (C) Transcript levels of p104, myogenin, and $\alpha$-actin and the protein level of p104 were determined in the absence (Undif.) or presence (Dif.) of differentiation medium by reverse transcription-polymerase chain reaction and Western blot analysis, respectively. The mRNA levels of p104 and differentiation markers were increased 5 days after the induction of differentiation. Levels of glyceraldehydes-3-phosphate dehydrogenase (GAPDH) transcript and actin were used as a control. (D) Interaction of p104 with Racl and CrkII was increased during the $\mathrm{C} 2 \mathrm{C} 12$ differentiation. $\mathrm{C} 2 \mathrm{C} 12$ cells were grown in differentiation media for 5 days and total protein was extracted. Lysates from undifferentiated or differentiated cells were immunoprecipitated with p104 antiserum, and then Western blot analysis was performed using anti-CrkII, anti-Racl, and anti-p104 antibodies. (E) The effect of p104 overexpression in the myotube differentiation. The C2C12 cells were transfected with p104 ((i)-(p)) and grown in the presence ((e)-(h), (m)-(p)) or absence ((a)-(d), (i)-(l)) of differentiation media. The photos were taken at the indicated days after the addition of differentiation media. 


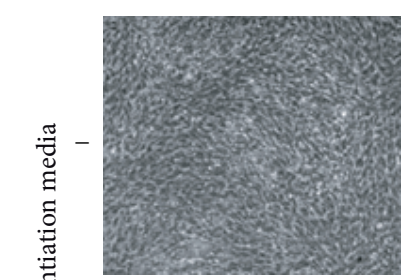

(a)

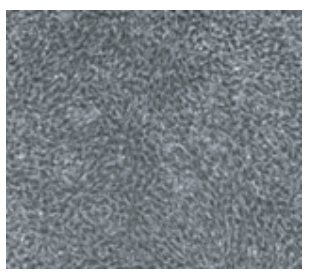

(b)

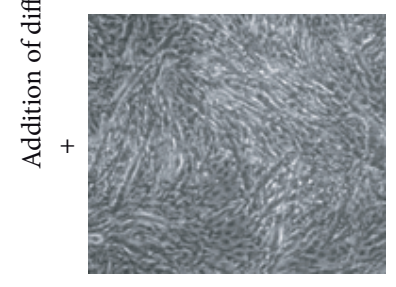

siRNA

GFP

(c)

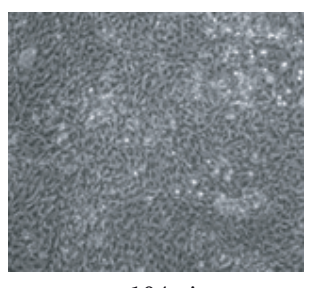

p104-si

(d)

(A)

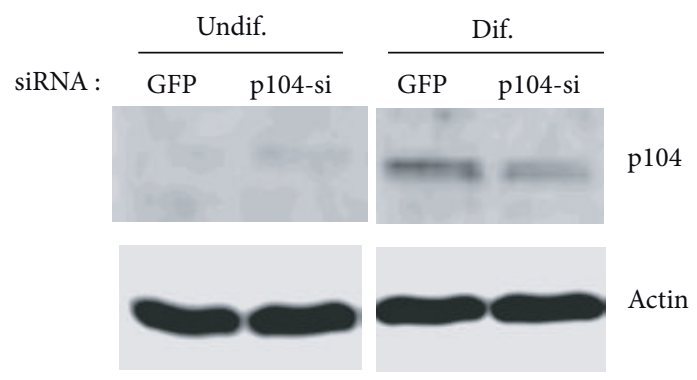

(B)

FIGURE 6: The effect of p104 siRNAs transfection in the myotube differentiation. (A) The $\mathrm{C} 2 \mathrm{C} 12$ cells were transfected with p104 siRNA ((b), (d)) and grown in the presence ((c), (d)) or absence ((a), (b)) of differentiation media. The photos were taken 4 days after siRNAs transfection. (B) The decrease of p104 protein in the differentiation condition was shown by Western blot analysis.

methods such as yeast two-hybrid screening, coimmunoprecipitation, and pull-down analysis (Figures 1 and 2). Also, colocalization of p104 and Rac1 proteins in NIH3T3 cells was confirmed by immunocytochemical studies (Figure 1(c)). Given the previous studies about p104 induced growth suppression through the upregulation of p2 $7^{\mathrm{Kip} 1}$ in NIH3T3 cells [1] and involvement of Racl in G1/S cell cycle transition by inducing cyclin D1 accumulation $[48,49]$, we could infer the significance of the interaction between the two proteins. Data from this study suggests that Racl might be a mediator of the relationship between p104 and p2 $7^{\text {kip1 }}$. p2 $7^{\text {kip }}$ inhibits the cyclin D-Cdk4/6 complexes, a key player in G1/S transition $[50,51]$. It has been reported that the Racl signaling pathway induced by integrin signaling resulted in a rapid reduction of the Cdk inhibitors, $\mathrm{p} 21^{\mathrm{CIP} 1}$ and $\mathrm{p} 27^{\mathrm{Kip} 1}$, by proteasomal degradation [52]. There is a possibility that p104 may suppress the cell cycle progression by inactivating the Racl, followed by the downregulation of cyclin $\mathrm{D}$ synthesis and inhibition of $\mathrm{p} 27^{\mathrm{Kip} 1}$ degradation. Another interesting question to be investigated is whether the interaction between p104 and Rac1 is dependent on the nucleotide binding status of Racl (i.e.,
GTP, GDP, or nucleotide free), since Racl is a Rho family small GTPase.

The activity of Racl was reduced by overexpression of p104 (Figure 4), even though the molecular mechanism of the reduction of the Racl activity is still unclear. The possible explanations are that p104 could be acting as an atypical GAP for Racl or that p104 binding to Racl prevents GEF access to Racl. Another explanation is based on our previous studies; overexpression of p104 inhibits the activity of PI3K by interaction with $\mathrm{p} 85 \alpha$ through the second and third proline-rich region of p104 [1]. Furthermore, it is known that Racl and its effector proteins such as Vav and Sos guaninenucleotide exchange factors work at the downstream in the growth factor-mediated PI3K pathway [53-56]. Therefore, it is plausible to think that p104 interacts with p85 through its proline-rich domain to inhibit PI3K activity and to subsequently reduce the Racl activity.

One of the most interesting findings in this study was that p104 can also interact with CrkII (Figure 3). CrkII is an adaptor protein known to interact with several proteins through either its $\mathrm{SH} 2$ or $\mathrm{SH} 3$ domains [57]. In this study, it was verified that CrkII can interact directly with p104 through its proline-rich region (Figure 3(c)). Ablation of this site and the carboxy-terminal of p104 functionally impaired the ability of p104 to reduce the activity of Racl (Figures 4(a) and 4(b)). These results indicate that these regions are functionally linked with CrkII and Racl in reducing the activity of Racl. Several reports have stated that CrkII preferentially activates the small GTPase Rac1 through DOCK180, a guanine-nucleotide exchange factor, and this regulation is achieved by the formation of a multiple protein complex with docking protein p130Cas $[32,33]$. We hypothesize that p104 also functions as a docking protein that can regulate the activity of Racl by making a complex with Racl, CrkII, as well as PI3K. However, this docking protein appears to have a negative role in regulating the activity of Racl, unlike the p130Cas. Even though it is not clear whether p104 could bind to Racl and CrkII simultaneously, it is possible that CrkII and Racl are sequestered spatiotemporally by binding to p104 under certain physiological conditions such as serum starvation. Further studies should be carried out to clear this aspect.

The overexpression of p104 facilitated $\mathrm{C} 2 \mathrm{C} 12$ differentiation (Figure 5(E)). Myoblasts differentiate into skeletal muscle cells by withdrawal from the cell cycle and subsequent expression of myotube-specific genes [58]. p104 might enhance this differentiation via its ability to block cell cycle because p104 appears to play a key role in cell cycle regulation [1]. In this case, p104 depletion may delay the ability of $\mathrm{C} 2 \mathrm{C} 12$ to stop proliferation when the cell was switched to a differentiation medium. Another possibility is related with the reports in which activated Racl prevents the withdrawal from the cell cycle and muscle differentiation, while dominant negative form of Racl induces differentiation [47]. The inhibitory effect of the constitutively active Racl protein on myogenesis is directly linked to the activation of the JNK pathway [59]. The direct interaction of CrkII with JNK is critical for Racl-induced JNK activation [39]. In this study, expression level of p104 was increased and the activity 
of Racl was decreased after the addition of differentiation medium (Figure 5). Because p104 could interact with CrkII and Racl and its amount was increased during the muscle cell differentiation, more CrkII and Racl could interact with increased p104 when $\mathrm{C} 2 \mathrm{C} 12$ myoblast differentiation was induced (Figure 5(D)). It is possible that an increase in the amount of p104 resulted in sequestering more Racl and CrkII from JNK during muscle differentiation. In fact, as shown in Figure 4(d), JNK activity was decreased by overexpression of p104. These data collectively support the idea that p104 may prevent the JNK activation by sequestering and reducing Racl activity during muscle differentiation.

$\begin{array}{ll}\text { Abbreviations } \\ \text { GAP: } & \text { GTPase-activating protein } \\ \text { GDI: } & \text { Guanine-nucleotide dissociation inhibitor } \\ \text { GEF: } & \text { Guanine-nucleotide exchanging factor } \\ \text { GST: } & \text { Glutathione S-transferase } \\ \text { JNK: } & \text { c-Jun N-terminal kinase } \\ \text { PAK: } & \text { p21-activated kinase } \\ \text { PI3K: Phosphoinositide 3-kinase } \\ \text { PLC } 1: \text { Phosphoinositol-specific phospholipase C } \gamma 1 \\ \text { SH2: } \quad \text { Src Homology domain } 2 \\ \text { SH3: } \quad \text { Src Homology domain } 3 .\end{array}$

\section{Conflict of Interests}

The authors declare that there is no conflict of interests regarding the publication of this paper.

\section{Acknowledgments}

This work was supported by a Korea Research Foundation Grant (KRF-2008-005-J00203) to Seung Hwan Hong, funded by the Korean Government (MOEHRD, Basic Research Promotion Fund). Ki Young Choi, Min Sup Lee, and Young Jun Cho were supported by a BK21 Research Fellowship from the Korean Ministry of Education.

\section{References}

[1] S. J. Han, J. H. Lee, K. Y. Choi, and S. H. Hong, "Novel p104 protein regulates cell proliferation through PI3K inhibition and p27Kip1 expression," BMB Reports, vol. 43, no. 3, pp. 199-204, 2010.

[2] S. J. Heasman and A. J. Ridley, "Mammalian Rho GTPases: new insights into their functions from in vivo studies," Nature Reviews Molecular Cell Biology, vol. 9, no. 9, pp. 690-701, 2008.

[3] A. Hall, "Rho GTpases and the actin cytoskeleton," Science, vol. 279, no. 5350, pp. 509-514, 1998.

[4] A. Hall, "The cellular functions of small GTP-binding proteins," Science, vol. 249, no. 4969, pp. 635-640, 1990.

[5] Y. Fukumoto, K. Kaibuchi, Y. Hori et al., "Molecular cloning and characterization of a novel type of regulatory protein (GDI) for the rho proteins, ras p21-like small GTP-binding proteins," Oncogene, vol. 5, no. 9, pp. 1321-1328, 1990.

[6] E. Vasyutina, B. Martarelli, C. Brakebusch, H. Wende, and C. Birchmeier, "The small G-proteins Racl and Cdc42 are essential for myoblast fusion in the mouse," Proceedings of the National Academy of Sciences of the United States of America, vol. 106, no. 22, pp. 8935-8940, 2009.

[7] K. Behrendt, J. Klatte, R. Pofahl et al., "A function for Racl in the terminal differentiation and pigmentation of hair," Development, vol. 139, no. 9, pp. 896-905, 2012.

[8] J. Kucharczak, S. Charrasse, F. Comunale et al., "R-cadherin expression inhibits myogenesis and induces myoblast transformation via Racl GTPase," Cancer Research, vol. 68, no. 16, pp. 6559-6568, 2008.

[9] D. A. Starr and M. Han, "ANChors away: an actin based mechanism of nuclear positioning," Journal of Cell Science, vol. 116, no. 2, pp. 211-216, 2003.

[10] O. Dorseuil, A. Vazquez, P. Lang, J. Bertoglio, G. Gacon, and G. Leca, "Inhibition of superoxide production in B lymphocytes by Rac antisense oligonucleotides," Journal of Biological Chemistry, vol. 267, no. 29, pp. 20540-20542, 1992.

[11] M. Daugaard, R. Nitsch, B. Razaghi et al., "Hacel controls ROS generation of vertebrate Racl-dependent NADPH oxidase complexes," Nature Communications, vol. 4, Article ID 2180, 20132013.

[12] K. Takaishi, A. Kikuchi, S. Kuroda, K. Kotani, T. Sasaki, and Y. Takai, "Involvement of rho p21 and its inhibitory GDP/GTP exchange protein (rho GDI) in cell motility," Molecular and Cellular Biology, vol. 13, no. 1, pp. 72-79, 1993.

[13] S. Woo, M. P. Housley, O. D. Weiner, and D. Y. Stainier, "Nodal signaling regulates endodermal cell motility and actin dynamics via Racl and Prexl," Journal of Cell Biology, vol. 198, pp. 941-952, 2012.

[14] A. Minden, A. Lin, F.-X. Claret, A. Abo, and M. Karin, "Selective activation of the JNK signaling cascade and c-Jun transcriptional activity by the small GTPses Rac and Cdc42Hs," Cell, vol. 81, no. 7, pp. 1147-1157, 1995.

[15] J. Ma, Y. Xue, W. Liu et al., "Role of activated rac1/cdc42 in mediating endothelial cell proliferation and tumor angiogenesis in breast cancer," PLoS One, vol. 8, Article ID e66275, 2013.

[16] X. Guo, M. Wang, J. Jiang et al., "Balanced Tiam1-rac1 and RhoA drives proliferation and invasion of pancreatic cancer cells," Molecular Cancer Research, vol. 11, pp. 230-239, 2013.

[17] B. Brenner, U. Koppenhoefer, C. Weinstock, O. Linderkamp, F. Lang, and E. Gulbins, "Fas- or ceramide-induced apoptosis is mediated by a Racl-regulated activation of Jun N-terminal kinase/p38 kinases and GADD153," Journal of Biological Chemistry, vol. 272, no. 35, pp. 22173-22181, 1997.

[18] P. Han, Y. Luan, Y. Liu et al., "Small interfering RNA targeting Racl sensitizes colon cancer to dihydroartemisinin-induced cell cycle arrest and inhibited cell migration by suppressing NFkappaB activity," Molecular and Cellular Biochemistry, vol. 379, pp. 171-180, 2013.

[19] A. J. Valente, T. Yoshida, R. A. Clark, P. Delafontaine, U. Siebenlist, and B. Chandrasekar, "Advanced oxidation protein products induce cardiomyocyte death via Nox2/Rac1/superoxidedependent TRAF3IP2/JNK signaling," Free Radical Biology and Medicine, vol. 60, pp. 125-135, 2013.

[20] W. Xie and H. R. Herschman, "Transcriptional regulation of prostaglandin synthase 2 gene expression by platelet-derived growth factor and serum," Journal of Biological Chemistry, vol. 271, no. 49, pp. 31742-31748, 1996.

[21] N. Clarke, N. Arenzana, T. Hai, A. Minden, and R. Prywes, "Epidermal growth factor induction of the c-jun promoter by a rac pathway," Molecular and Cellular Biology, vol. 18, no. 2, pp. 1065-1073, 1998. 
[22] C. S. Hill, J. Wynne, and R. Treisman, “The Rho family GTPases RhoA, Racl, and CDC42Hs regulate transcriptional activation by SRF," Cell, vol. 81, no. 7, pp. 1159-1170, 1995.

[23] S. Montaner, R. Perona, L. Saniger, and J. C. Lacal, "Multiple signalling pathways lead to the activation of the nuclear factor $\kappa \mathrm{B}$ by the Rho family of GTPases," Journal of Biological Chemistry, vol. 273, no. 21, pp. 12779-12785, 1998.

[24] C. Gauthier-Rouvière, E. Vignal, M. Mériane, P. Roux, P. Montcourier, and P. Fort, "RhoG GTPase controls a pathway that independently activates Racl and Cdc42Hs," Molecular Biology of the Cell, vol. 9, no. 6, pp. 1379-1394, 1998.

[25] R.-G. Qiu, J. Chen, D. Kirn, F. McCormick, and M. Symons, "An essential role for Rac in Ras transformation," Nature, vol. 374, no. 6521, pp. 457-459, 1995.

[26] P. J. Keely, J. K. Westwick, I. P. Whitehead, C. J. Der, and L. V. Parise, "Cdc42 and Rac1 induce integrin-mediated cell motility and invasiveness through PI(3)K," Nature, vol. 390, no. 6660, pp. 632-636, 1997.

[27] S. Lewis-Saravalli, S. Campbell, and A. Claing, "ARF1 controls Racl signaling to regulate migration of MDA-MB-231 invasive breast cancer cells," Cell Signalling, vol. 25, pp. 1813-1819, 2013.

[28] A. L. Bishop and A. Hall, "Rho GTPases and their effector proteins," Biochemical Journal, vol. 348, no. 2, pp. 241-255, 2000.

[29] D. Diekmann, A. Abo, C. Johnston, A. W. Segal, and A. Hall, "Interaction of Rac with p67(phox) and regulation of phagocytic NADPH oxidase activity," Science, vol. 265, no. 5171, pp. 531-533, 1994.

[30] P. B. van Hennik, J. P. Ten Klooster, J. R. Halstead et al., “The Cterminal domain of Racl contains two motifs that control targeting and signaling specificity," Journal of Biological Chemistry, vol. 278, no. 40, pp. 39166-39175, 2003.

[31] A. E. Karnoub, C. J. Der, and S. L. Campbell, “The insert region of Racl is essential for membrane ruffling but not cellular transformation," Molecular and Cellular Biology, vol. 21, no. 8, pp. 2847-2857, 2001.

[32] E. Kiyokawa, Y. Hashimoto, S. Kobayashi, H. Sugimura, T. Kurata, and M. Matsuda, "Activation of Racl by a Crk SH3binding protein, DOCK180," Genes and Development, vol. 12, no. 21, pp. 3331-3336, 1998.

[33] H. W. Smith, P. Marra, and C. J. Marshall, "uPAR promotes formation of the p130Cas-Crk complex to activate Rac through DOCK180," Journal of Cell Biology, vol. 182, no. 4, pp. 777-790, 2008.

[34] H. Feng, B. Hu, K.-W. Liu et al., "Activation of Racl by Srcdependent phosphorylation of Dock180Y1811 mediates PDGFR $\alpha$-stimulated glioma tumorigenesis in mice and humans," Journal of Clinical Investigation, vol. 121, no. 12, pp. 4670-4684, 2011.

[35] B. J. Mayer, M. Hamaguchi, and H. Hanafusa, "A novel viral oncogene with structural similarity to phospholipase C," Nature, vol. 332, no. 6161, pp. 272-275, 1988.

[36] M. Matsuda, C. T. Reichman, and H. Hanafusa, "Biological and biochemical activity of v-Crk chimeras containing the $\mathrm{SH} 2 / \mathrm{SH} 3$ regions of phosphatidylinositol-specific phospholipase C- $\gamma$ and Src," Journal of Virology, vol. 66, no. 1, pp. 115-121, 1992.

[37] S. M. Feller, "CrK family adaptors-signalling complex formation and biological roles," Oncogene, vol. 20, no. 44, pp. 6348-6371, 2001.

[38] S. Gelkop, Y. Babichev, and N. Isakov, "T cell activation induces direct binding of the Crk adapter protein to the regulatory subunit of phosphatidylinositol 3-kinase (p85) via a complex mechanism involving the Cbl protein," Journal of Biological Chemistry, vol. 276, no. 39, pp. 36174-36182, 2001.

[39] S. E. Girardin and M. Yaniv, "A direct interaction between JNK1 and CrkII is critical for Racl-induced JNK activation," The EMBO Journal, vol. 20, no. 13, pp. 3437-3446, 2001.

[40] N. Nakashima, D. W. Rose, S. Xiao et al., “The functional role of CrkII in actin cytoskeleton organization and mitogenesis," Journal of Biological Chemistry, vol. 274, no. 5, pp. 3001-3008, 1999.

[41] S. Antoku and B. J. Mayer, "Distinct roles for Crk adaptor isoforms in actin reorganization induced by extracellular signals," Journal of Cell Science, vol. 122, no. 22, pp. 4228-4238, 2009.

[42] S. J. Han, J. H. Lee, S. H. Hong et al., "AP180 binds to the C-terminal SH2 domain of phospholipase C- $\gamma 1$ and inhibits its enzymatic activity," Biochemical and Biophysical Research Communications, vol. 290, no. 1, pp. 35-41, 2002.

[43] C. L. Williams, "The polybasic region of Ras and Rho family small GTPases: a regulator of protein interactions and membrane association and a site of nuclear localization signal sequences," Cellular Signalling, vol. 15, no. 12, pp. 1071-1080, 2003.

[44] Y. A. Abassi and K. Vuori, "Tyrosine 221 in Crk regulates adhesion-dependent membrane localization of Crk and Rac and activation of Rac signaling," EMBO Journal, vol. 21, no. 17, pp. 4571-4582, 2002.

[45] A. M. Vallés, M. Beuvin, and B. Boyer, "Activation of Racl by paxillin-Crk-DOCK180 signaling complex is antagonized by Rap1 in migrating NBT-II cells," Journal of Biological Chemistry, vol. 279, no. 43, pp. 44490-44496, 2004.

[46] O. A. Coso, M. Chiarielio, J.-C. Yu et al., "The small GTPbinding proteins racl and $\mathrm{Cdc} 42$ regulate the activity of the JNK/SAPK signaling pathway," Cell, vol. 81, no. 7, pp. 1137-1146, 1995.

[47] H. Heller, E. Gredinger, and E. Bengal, "Racl inhibits myogenic differentiation by preventing the complete withdrawal of myoblasts from the cell cycle," Journal of Biological Chemistry, vol. 276, no. 40, pp. 37307-37316, 2001.

[48] J. K. Westwick, Q. T. Lambert, G. J. Clark et al., "Rac regulation of transformation, gene expression, and actin organization by multiple, PAK-independent pathways," Molecular and Cellular Biology, vol. 17, no. 3, pp. 1324-1335, 1997.

[49] C. Yang, E. A. Klein, R. K. Assoian, and M. G. Kazanietz, "Heregulin $\beta 1$ promotes breast cancer cell proliferation through Rac/ERK-dependent induction of cyclin D1 and p21Cip1," Biochemical Journal, vol. 410, no. 1, pp. 167-175, 2008.

[50] K. Polyak, M.-H. Lee, H. Erdjument-Bromage et al., "Cloning of p27(Kip1), a cyclin-dependent kinase inhibitor and a potential mediator of extracellular antimitogenic signals," Cell, vol. 78, no. 1, pp. 59-66, 1994.

[51] H. Toyoshima and T. Hunter, "p27, A novel inhibitor of G1 cyclin-Cdk protein kinase activity, is related to p21," Cell, vol. 78, no. 1, pp. 67-74, 1994.

[52] W. Bao, M. Thullberg, H. Zhang, A. Onischenko, and S. Strömblad, "Cell attachment to the extracellular matrix induces proteasomal degradation of p21CIP1 via Cdc42/Racl signaling," Molecular and Cellular Biology, vol. 22, no. 13, pp. 4587-4597, 2002.

[53] C. D. Nobes, P. Hawkins, L. Stephens, and A. Hall, "Activation of the small GTP-binding proteins rho and rac by growth factor receptors," Journal of Cell Science, vol. 108, no. 1, pp. 225-233, 1995. 
[54] B. Fine, C. Hodakoski, S. Koujak et al., "Activation of the PI3K pathway in cancer through inhibition of PTEN by exchange factor P-REX2a," Science, vol. 325, no. 5945, pp. 1261-1265, 2009.

[55] J. Han, K. Luby-Phelps, B. Das et al., "Role of substrates and products of PI 3-kinase in regulating activation of Rac-related guanosine triphosphatases by Vav," Science, vol. 279, no. 5350, pp. 558-560, 1998.

[56] A. S. Nimnual, B. A. Yatsula, and D. Bar-Sagi, "Coupling of Ras and Rac guanosine triphosphatases through the Ras exchanger Sos," Science, vol. 279, no. 5350, pp. 560-563, 1998.

[57] S. Okada and J. E. Pessin, "Interactions between Src homology $(\mathrm{SH}) 2 / \mathrm{SH} 3$ adapter proteins and the guanylnucleotide exchange factor SOS are differentially regulated by insulin and epidermal growth factor," Journal of Biological Chemistry, vol. 271, no. 41, pp. 25533-25538, 1996.

[58] H. Weintraub, R. Davis, S. Tapscott et al., "The myoD gene family: nodal point during specification of the muscle cell lineage," Science, vol. 251, no. 4995, pp. 761-766, 1991.

[59] M. Meriane, P. Roux, M. Primig, P. Fort, and C. GauthierRouviere, "Critical activities of Racl and Cdc42Hs in skeletal myogenesis: antagonistic effects of JNK and p38 pathways," Molecular Biology of the Cell, vol. 11, no. 8, pp. 2513-2528, 2000. 

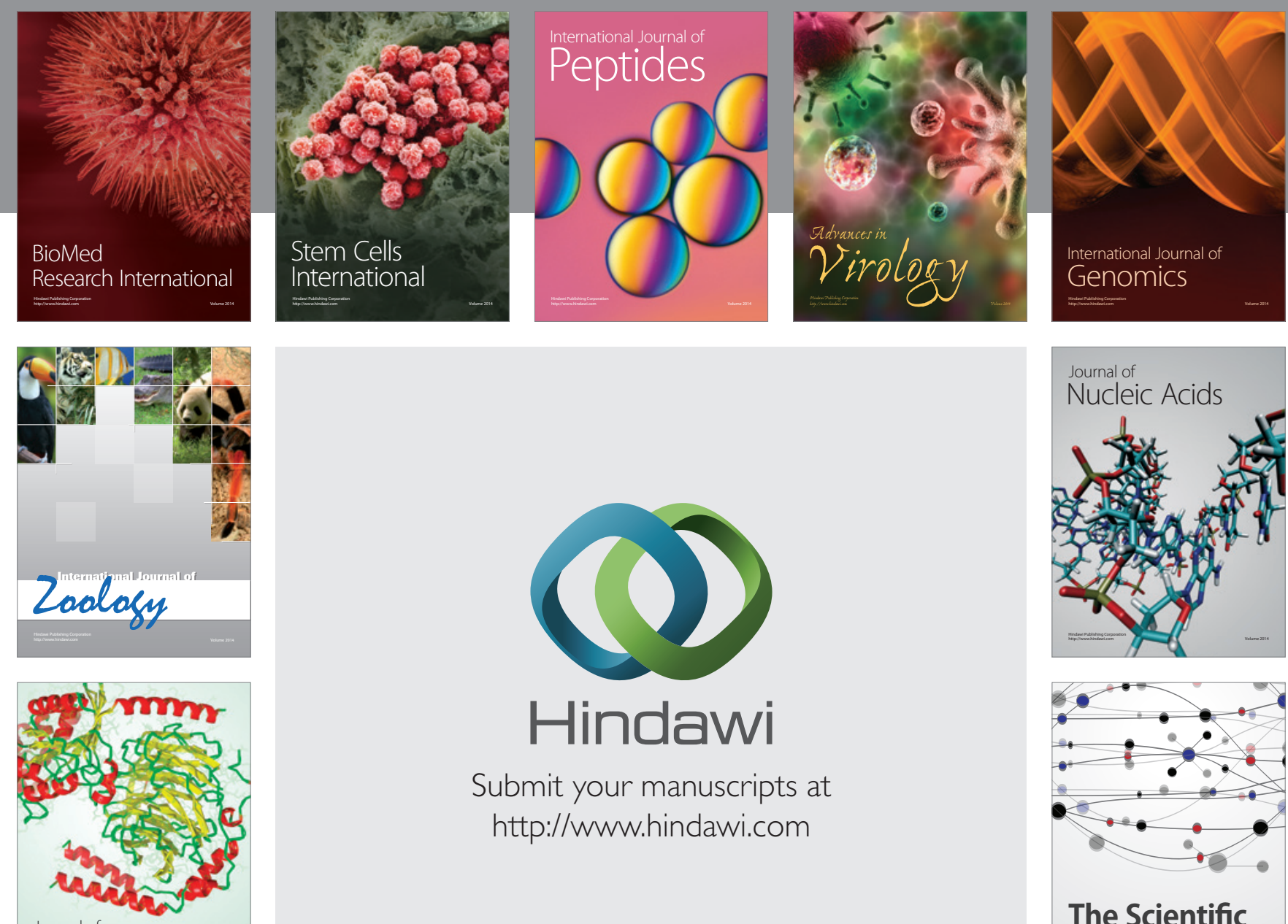

Submit your manuscripts at

http://www.hindawi.com

Journal of
Signal Transduction
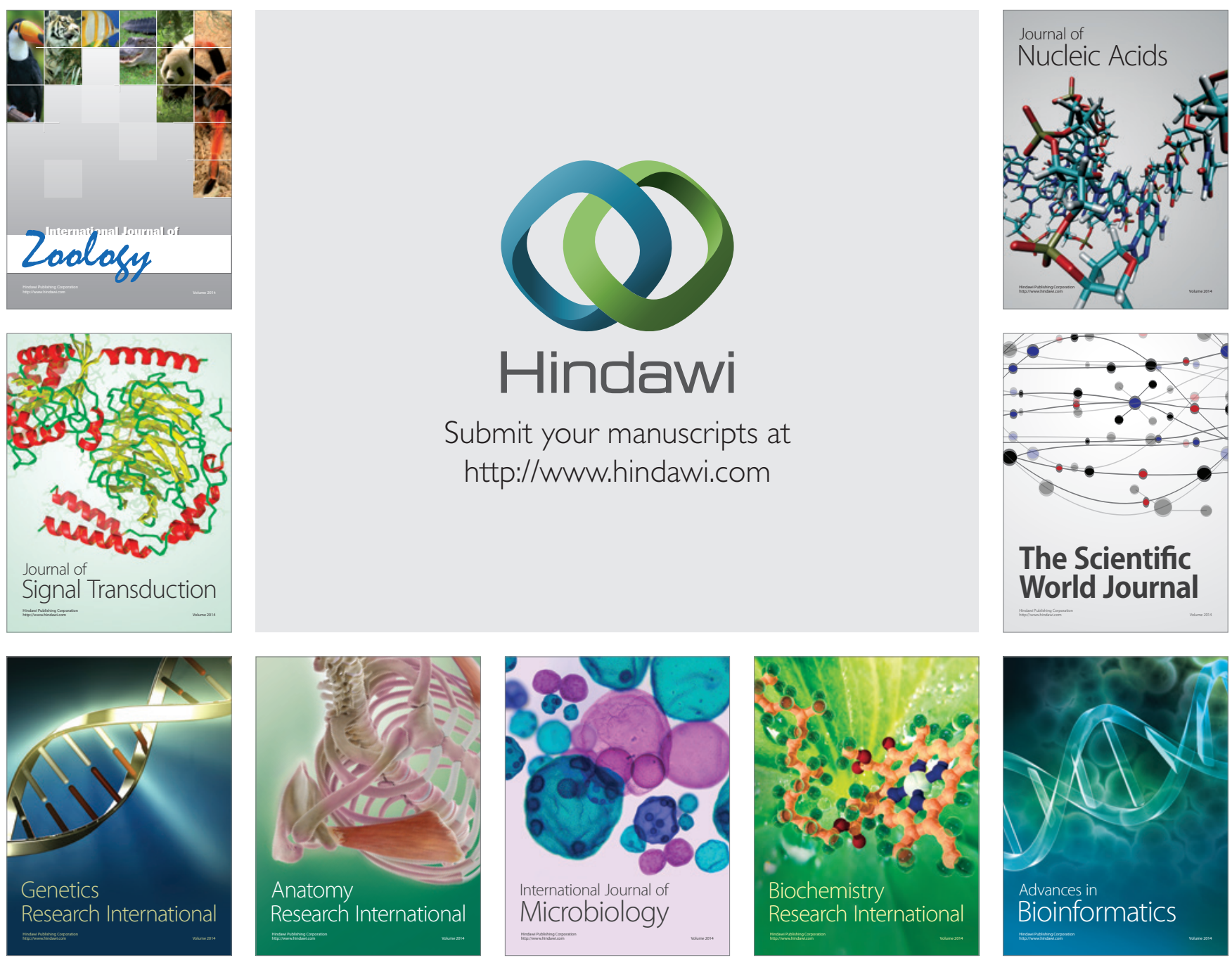

The Scientific World Journal
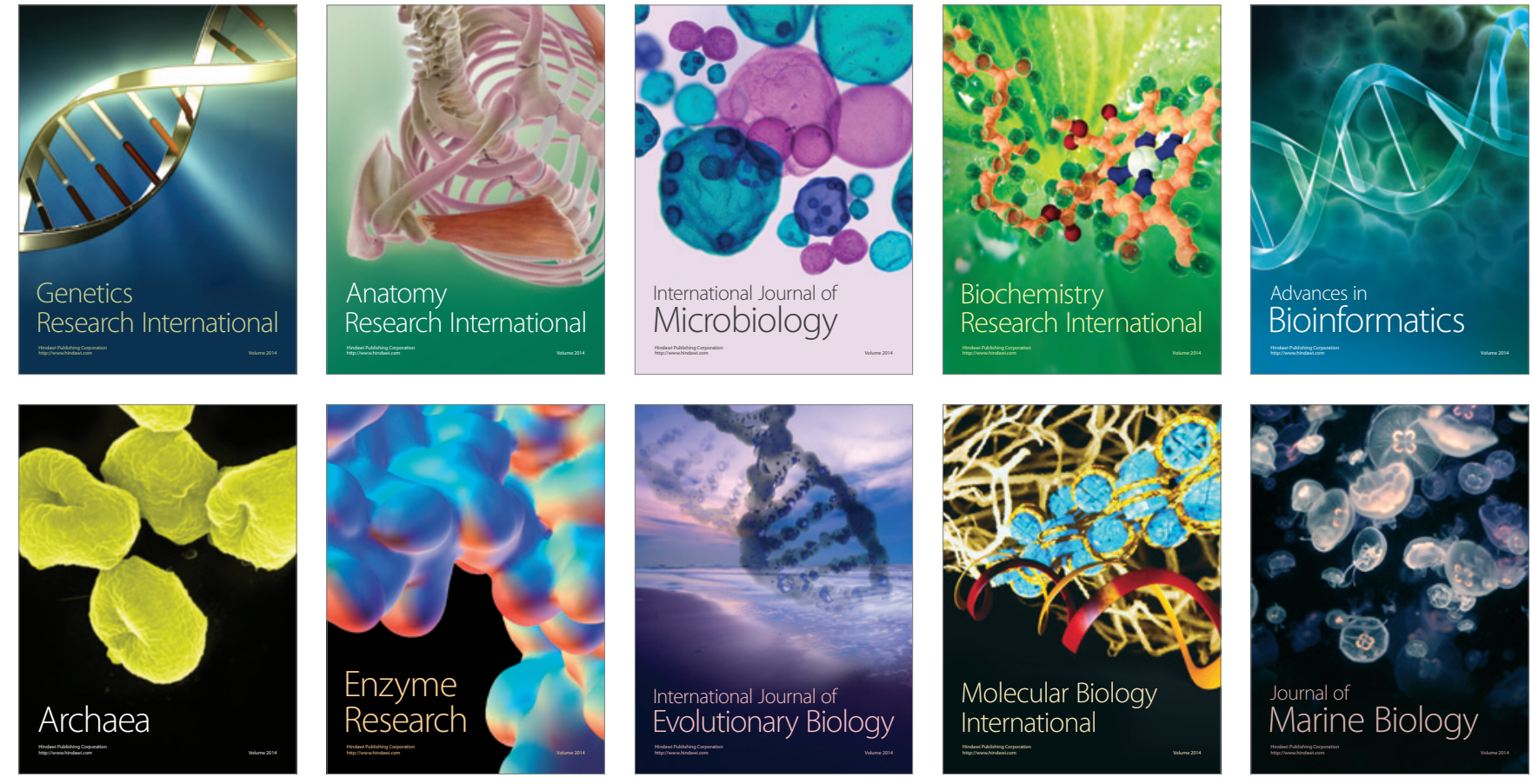